\title{
Analysis on the Pronunciation of " $T$ " in Chinese English
}

\author{
YI Li, KANG Shi-hui \\ China Agricultural University, Beijing, China
}

\begin{abstract}
English has been prevailingly learnt in China since the beginning of the 1980s. Nowadays, more and more people take English as their second language, and some of them are even bilingual. This phenomenon aroused the interest of many linguists, especially on the point of phonetic achievement in second language learning. According to some of the L2 theories, viz. the transfer theory, people are apt to adopt the closest pronunciation of their tongue language in their second language acquisition. In this paper, the author focused on the pronunciation of " $\mathrm{T}$ " in Chinese English. With the CD attached the book American Accent Training (2000) as a cardinal pronunciation, together with two recorded native speakers' voices, the author made a comparison between the cardinal ones and the records the author drew from 10 Chinese speaker objects. The result shows that even though the Chinese speaker objects are all proficient English users, there still exists some bias in their production of the consonant " $T$ ".

Keywords: consonant, allophone, Chinese English, bias, L2 transfer
\end{abstract}

\section{Introduction}

This paper made an attempt to analyze the pattern of the Chinese English speakers on their pronunciation of " $\mathrm{T}$ ". With the sounds drawn from the CD record attached the book American Accent Training (2000), together with records of two native speakers, a comparison between the cardinal standards and the those drawn from 10 Chinese speaker objects has been made. The result shows that even though the Chinese speaker objects are all proficient English users, there still exists some bias in their pronunciation of the consonant " $T$ ".

Speaking of the pronunciation in any language learning, we usually would not use the term "wrong" as we do in morphologic and syntax learning, but rather we are more likely to use the term "bad". Actually, compared with morphology and syntax, phonetic is harder to measure. You can tell a wrong spelling or a wrong syntax at the first glimpse, while the pronunciation is fleeting and sometimes idiosyncratic, it is almost an impossible mission to grasp the regular pattern and to make a judgment and therefore, it is hard to make a further improvement in language learning as well as teaching. This paper is an attempt to improve the L2 language study from the aspect of phonetic.

In China, more and more people take English as their second language nowadays. The beginning age of learning English tends to be younger in these years. In some big cities, Shanghai or Beijing, many people encourage their children to learn English in nursery school. People admit the English proficiency among young people is much higher today, yet there is some pattern in their pronunciation which is biased by their native language. The pronunciation of " $T$ " is only a case in point.

The reason of taking the $\mathrm{CD}$ record as a cardinal pronunciation is due to the lack of so-called standard

YI Li, associate professor, Ph.D., Foreign Language Department, China agricultural university. KANG Shi-hui, postgraduate student, Foreign Language Department, China agricultural university. 
American English. There exist some accents in American English, and no one claims to be the standard American English, as the Standard Chinese does. The CD record attached the book American Accent Training claims to be "the way a professor lectures, a national newscasters broadcast and a way that is comfortable and familiar to the most majority of people" (Cook, 2012, p. 5). Besides, two native speakers were recorded as well. Their voices are taken as a reference.

The 10 Chinese speaker objects are all high proficient English speakers. On average, they all learn English more than 15 years. Two of them are senior interpreters, one is a university English professor, and the other seven people are all post graduate students, among whom there are four persons who have lived in the United States. Instead of the beginners, the advanced learners have been chosen only because their pronunciation is stable. It is more likely to find the regular pattern about the Chinese English.

The reading materials are designed to meet the target of pronunciation "T". There are words which were recorded within a carrier sentence, such as "say again". There are also 16 sentences with " $\mathrm{T}$ " imbedded in. A perception experiment was conducted afterwards. It will be discussed in part three.

\section{Literature Review}

In this part, the development of the term "Chinese English" will be firstly presented, and then the pronunciation of "T" and then the concerned studies will be put forward.

The notion of "Chinese English" was first brought up by GE Chuan-gui (1980) and completed further in the last three decades by other scholars (SUN, 1989; RONG, 1991; LI, 1993; DU, 1998). They all focused on morphology, especially loan words. WEN (2007) talked about the Chinese English from the aspect of phonetics, yet her research was not based on the experimental study, and the conclusion was not drawn from data analysis. WANG (2010) and XIONG (2006) conducted some experimental researches on Chinese English, but they focused on intonation only.

As for the pronunciation of " $\mathrm{T}$ ", it has been studied a lot since it is also a point for the native speakers. That is the reason to take it in this research. Consonant " $\mathrm{T}$ " has several allophones according to different places of articulation. Ladefoged (2003) gave a good conclusion: The default allophone is transcribed as [ $\mathrm{t}^{\mathrm{h}}$ ] when it happens as initials, which is similar to the initial " $\mathrm{T}$ " in mandarin. When it is preceded by a voiceless consonant, it will sound as [t]. Actually, this mainly refers to "ST" combination in English. When it follows a stressed vowel and proceeds an unstressed syllable (except [n]), it will be pronounced as [d]. However, the situation will not be discussed in this paper because a voiceless consonant usually becomes voiced when it appears between two vowels. It is due to co-articulation and happens in Chinese too. Besides, it usually happens in a speech instead of within word, which is not the case with other five situations. There are other three allophones of "T", which are more "American-like". Many American people (especially young people) pronounce it very differently in the words pity, letter, and better, in which " $\mathrm{T}$ " happens between two vowels and in the unstressed syllables. Here "T" is a tap $[r]$ with the tongue tip touching against the alveolar ridge very quickly. When it is a coda, for instance in the word pit, especially at the end of a sentence, " $\mathrm{T}$ " sounds like a glottal stop [?] plus a short [t], and sometimes this [t] will miss. Ladefoged himself would pronounce mat as [mæ?t]. The last situation is when "T" is pronounced as a glottal stop together with a nasal consonant [?n] while preceding a nasal consonant, like beaten, kitten, fattens [bi'?n, ki'?n fæ'?ñ]. The allophones happen partly due to assimilation and partly due to the so-called "ease of articulation". 


\section{Data Analysis}

\section{The Analysis on the Production}

In Table 1, CS refers to the Chinese speakers, and "TOTAL G" refers to the total amount of good pronunciation of Chinese speakers. Analyzing Table 1, the data will be divided into three categories. The first allophone $\left[\mathrm{t}^{\mathrm{h}}\right]$, the default of "T", and the allophone $[\mathrm{t}]$ could be $100 \%$ good pronunciation among the native speakers and Chinese English speakers as well. These two allophones all could be found in Standard Chinese (a.k.a. Mandarin). There is not a voiced alveolar stop [d] in Standard Chinese phoneme inventory (Duanmu, 2007). The minimal contrast exists only between the voiceless $[t]$ and the aspirated $\left[t^{\mathrm{h}}\right]$. Chinese speakers pronounce the voiced counterpart [d] only when [t] happens in the midst of two vowels, which is the same with that in English. The vibration of vocal cord caused by the vowel preceding the " $\mathrm{T}$ " will not stop for the consonant followed, not to mention there is an anticipated vibration ahead. It is unreasonable to imagine a vocal cord vibrates, then stops and vibrates again in a fast speech. Theory to explain it is called "the ease of articulation". Taking the idiosyncrasy into consideration, a conclusion can be reached: Most Chinese speakers will pronounce the first two allophones of "T" good.

Table 1

The Good Pronunciation of " $T$ ” Allophones

\begin{tabular}{|c|c|c|c|c|c|c|}
\hline & $\mathrm{t}^{\mathrm{h}}$ & $\mathrm{t}$ & r & ? & ?n & $\operatorname{good}(\%)$ \\
\hline TOTAL & 10 & 10 & 10 & 10 & 15 & -- \\
\hline Native 1 & 10 & 10 & 10 & 10 & 13 & 96 \\
\hline Native 2 & 10 & 10 & 9 & 10 & 13 & 94 \\
\hline CS 1 & 10 & 10 & 9 & 0 & 7 & 65 \\
\hline $\mathrm{CS} 2$ & 10 & 10 & 9 & 2 & 10 & 74 \\
\hline CS 3 & 10 & 10 & 9 & 0 & 7 & 65 \\
\hline $\mathrm{CS} 4$ & 10 & 10 & 8 & 1 & 8 & 67 \\
\hline CS 5 & 10 & 10 & 0 & 0 & 6 & 47 \\
\hline CS 6 & 10 & 10 & 7 & 0 & 7 & 61 \\
\hline CS 7 & 10 & 10 & 7 & 3 & 8 & 69 \\
\hline CS 8 & 10 & 10 & 9 & 2 & 8 & 71 \\
\hline CS 9 & 10 & 10 & 7 & 0 & 8 & 64 \\
\hline CS 10 & 10 & 10 & 7 & 0 & 7 & 62 \\
\hline TOTAL G & 100 & 100 & 81 & 8 & 76 & -- \\
\hline
\end{tabular}

As for the allophone $[r]$ and $[? n]$, the results are very much close for the most Chinese speakers objects. There is an exception: The object CS 5 cannot pronounce $[r]$ in a good way but he can pronounce [?n] good in some cases. They will be explained separately: Firstly, the co-articulation plays a key role in [?n]. When an independent nasal syllable follows, it is very easy to produce the allophone [?n]. Both [t] and [n] have features of [-back] and [+coronal], and the two gestures will overlap, with the first one holding a gesture and the second one articulating. It is a universal rule during the articulation. Actually, it is hard to produce it in other way. The faster the speech is, the easier it will produce. Only in a slow and very clear pronunciation, the aspirated $\left[\mathrm{t}^{\mathrm{h}}\right]$ will appear before a nasal syllable. Secondly, the allophone $[r]$ is in a different case. It is mainly an American accent. It will be talked about later in perception part.

The glottal stop allophone of "T" happened at the end of a word or a speech has the lowest "good" results 
compared with the others. The glottal stop [?] in Standard Chinese only happens in initials when followed with a vowel, like in the word [xi?an] “西安” (place name). Otherwise, it will be regarded as a single character in China [xian] “先” (first). It never appears as a coda which only happens in some Chinese dialects. Standard Chinese is monosyllabic language, with an initial consonant and a vowel rhyme, sometimes with a nasal consonant coda ([n] and [n] only, that is why they produce [?n] more easily). Hence, Chinese speakers are accustomed to put a vowel instead of a glottal stop at the coda position. According to the personal teaching experience, the students from Guangdong province in the southern part of China produce it good partly because there is glottal stop coda in Cantonese. It needs further research to provide more evidences.

The spectrograms in Figure 1 show the word "forgotten" pronounced by native speaker 1 and CS 5 respectively. The highlighted parts are " $\mathrm{T}$ " position. The fundamental frequency disconnects in both of their spectrum, for the native speaker (left), a glottal stop preceding a nasal; and for the Chinese speaker (right) an obvious aspiration following the stop.
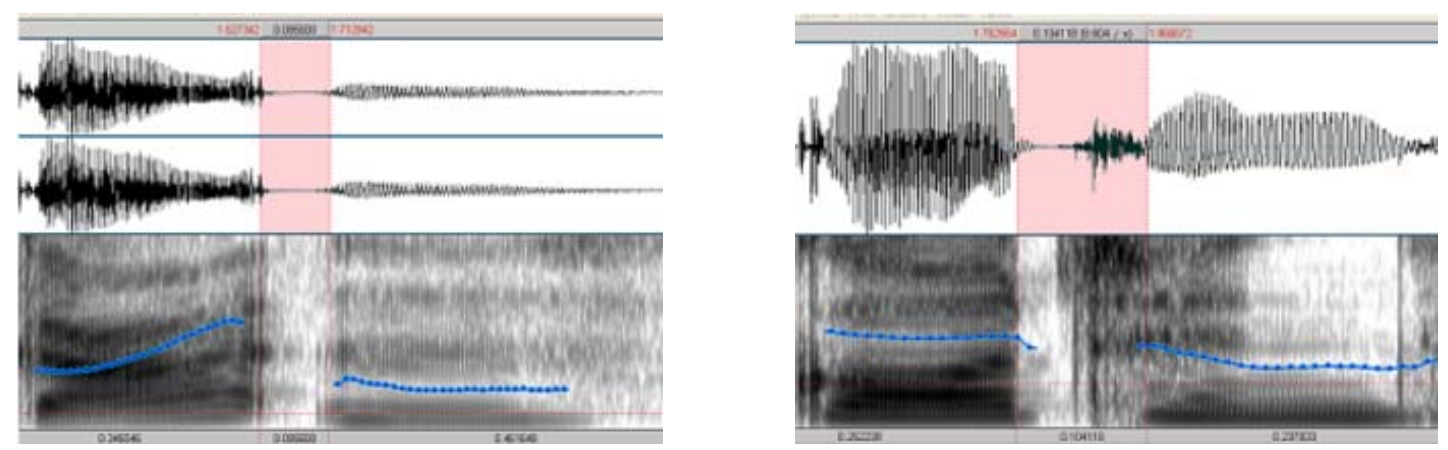

Figure 1. The spectrograms of the word "forgotten" produced by native speaker 1 (left) and CS 5 (right).

The left spectrogram in Figure 2 is the pronunciation of "T" in "what it" pronounced by native speaker 1. There is a disconnected fundamental frequency, but the formants are clear in the domain from which can be deduced that there is a vibration in vocal cord. CS 5's fundamental frequency in the right spectrogram is disconnected but the formants are unclear, and the energy is strong. It means there is vibration but it is not stable and there is aspiration that causes energy release.
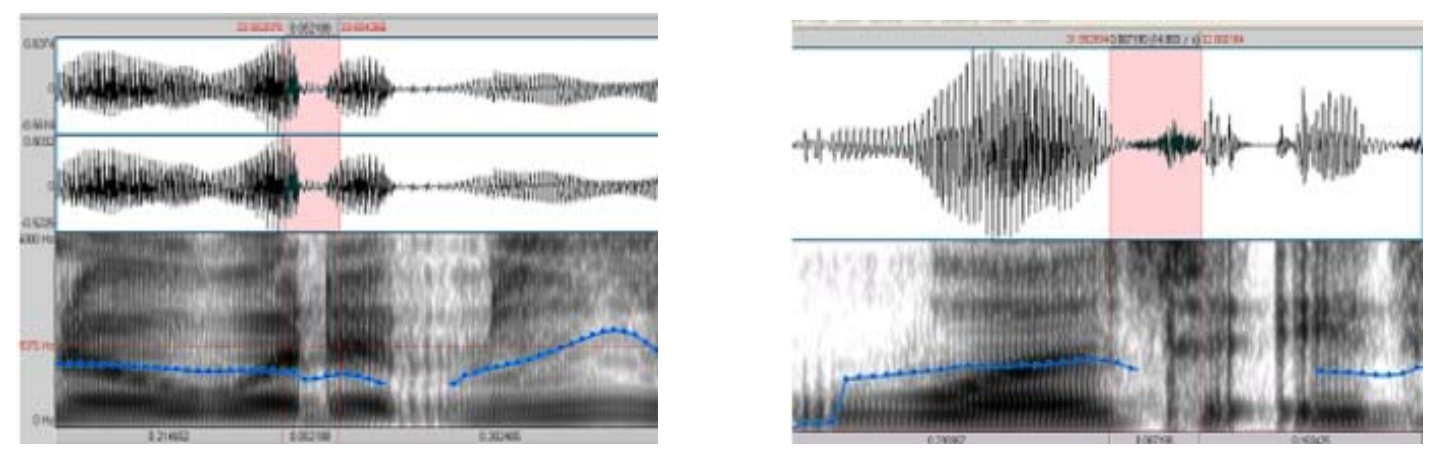

Figure 2. The pronunciations of "T" in "what it" pronounced by native speaker 1 (left) and CS 5 (right).

\section{The Analysis on the Perception}

The second part of our research is the perception study carried out by the second author. In Table 2, we will find that the objects can $100 \%$ distinguish $[\mathrm{t}]-\left[\mathrm{t}^{\mathrm{h}}\right]$ and $[\mathrm{r}]-\left[\mathrm{t}^{\mathrm{h}}\right]$, which matches the conclusion drawn in part one. As for the contrast between $[r]-[d]$ and $[r]-[t]$, except one native speaker, $100 \%$ objects cannot distinguish 
them. There is not a phoneme $[\mathrm{r}]$ in the phoneme inventory of Standard Chinese, and nor the minimal contrast between [d] and [t]. Therefore, we deduce, Chinese speakers produce [t] or [d] (mostly the former one) when they try to produce $[r]$. When it happens in a fast speech, $[\mathrm{t}]$ or $[\mathrm{d}]$ will change into $[r]$. They share the same place of articulation. When [t] happens in the midst of vowels, it will be co-articulated with vibration of vocal cord and change into [d]. When [d] is in an unstressed syllable, it will not hold a total stop gesture. The tip of tongue touches the alveolar very quickly and $[r]$ comes into being. That explains why people can produce it very good in most cases. As for the object of CS 5, we checked his pronunciation later and found he produced all the $[\mathrm{r}]$ with aspiration. In his understanding, " $\mathrm{T}$ " is produced only with one allophone, that is $\left[\mathrm{t}^{\mathrm{h}}\right]$ with aspiration. He adopted this pronunciation on the basis of his own recognition instead of imitation to the native speakers. After he realized that, he acquired the accent at once.

The most interesting part of the study lies in the distinction of [?]-[t(ə)], 100\% objects can tell the differences, yet in their speeches, especially during the fast or casual ones, Chinese people make bad pronunciations a lot, esp. in fast speech, so is the case of $[? \mathrm{n}]-\left[\mathrm{t}^{\mathrm{h}} \mathrm{n}\right]$. Even repeating the same text materials, an insertion of a schwa [ə] or an aspiration after [t] will happen here or there. We call it as a negative transfer according to the L2 transfer theory.

Table 2

The Perception of " $T$ " Allophones

\begin{tabular}{|c|c|c|c|c|c|c|c|}
\hline & t--d & $t--t^{h}$ & f--d & e--t & $\int--t^{h}$ & ?--t(ə) & ?n-- $t^{h} n$ \\
\hline Native 1 & + & + & + & + & + & + & + \\
\hline Native 2 & + & + & - & - & + & + & + \\
\hline CS 1 & - & + & - & - & + & + & + \\
\hline $\mathrm{CS} 2$ & + & + & - & - & + & + & + \\
\hline CS 3 & - & + & - & - & + & + & + \\
\hline CS 4 & - & + & - & - & + & + & + \\
\hline CS 5 & - & + & - & - & + & + & + \\
\hline CS 6 & - & + & - & - & + & + & + \\
\hline CS 7 & - & + & - & - & + & + & + \\
\hline CS 8 & - & + & - & - & + & + & + \\
\hline CS 9 & + & + & - & - & + & + & + \\
\hline CS 10 & - & + & - & - & + & + & + \\
\hline
\end{tabular}

\section{Conclusion}

Through the data analysis, we can draw a regular pattern of Chinese speakers on their pronunciation of " $T$ ": For the allophones $\left[\mathrm{t}^{\mathrm{h}}\right],[\mathrm{t}]$ and $[\mathrm{d}]$, all the people can pronounce them good. For the allophone of tap $[\mathrm{r}]$ and $[? n]$, in most cases, people produce it good, but not all the time. As for the allophone and the allophone of the glottal stop [?] at the end of word or speech, it is hard for people to make it good, which, combined with the insertion of a schwa [ə], represents the distinguished feature of Chinese English.

\section{References}

Cook, A. (2012). American accent training (2nd ed.). Hauppauge: Barron's Educational Series.

DU, Z. M. (1998). Zhongguo yingyu wenti ji qita (The English teaching issues in China and other problems). Foreign Language Education, 19, 6-14.

Duanmu, S. (2007). The phonology of standard Chinese (2nd ed.). New York: Oxford University Press. 
GE, C. G. (1980). Mantan you hanyiying wenti (Analysis of translations from Chinese to English). Chinese Translation, 2, 1-8.

Jacewicz, E., Fox, R. A., \& Lyle, S. (2008). Variation in stop consonant voicing in two regional varieties of American English. The Journal of the Acoustical Society of America, 124. Retreived from http://www.biomedsearch.com/nih/Variation-in-stop-consonant-voicing/19063347.html

Ladefoged, P. (2001). Vowels and consonants. Malden: Blackwell.

Ladefoged, P. (2003). Phonetics data analysis: An introduction to fieldwork and instrumental technique. Malden: Blackwell.

Ladefoged, P. (2009). A course in phonetics. Beijing: Foreign Language teaching and Research Press.

LI, W. Z. (1993). Zhongguo yingyu yu zhonguoshi yingyu (China English and Chinglish). Foreign Language Teaching and Research, 3, 18-24.

RONG, P. (1991). Zhongguo yingyu shi keguan cunzai (The existence of China English). Journal of PLA University of, 1, 1-8.

SUN, L. (1989). Yingyu guobie yuti de yanjiu: Guanyu zai zhongguo (Analysis of English varieties based on countries: The English in China). Foreign Language, 2, 17-23.

WANG, X. (2010). Zhongguo yingyu yunlv yanjiu (The intonation pattern of Chinese English) (Doctoral dissertation). China Academy of Social Science, Beijing.

WEN, Q. F. (2007). Zhongguo waiyu jiaoxue (The English education in China). Beijing: Foreign Language Teaching and Research Press.

XIONG, Z. Y. (2006, July 27th). Yunlv yanjiu de qianyan he tedian (Latest development and features of rhythmic). Newspaper of Chinese Academy of Social Science, p. 3.

XU, C. X., \& XU, Y. (2003). Effects of consonant aspiration on Mandarin tones. Journal of the International Phonetic Association, 33, 165-181. 